\title{
Um ensaio reflexivo das novas tecnologias na educação do ensino superior
}

\section{Resumo}

As mudanças estão ocorrendo cada vez mais rápido, a tecnologia continua em constante atualização, e a sociedade, seus costumes, valores, crenças, enfim, a sua cultura, têm que ir se adaptando e se reestruturando dia-a-dia. A educação entra nesta realidade como um processo conservador e, ao mesmo tempo, transformador na transmissão de conhecimento e cultura. A mídia agiliza e democratiza este processo, à medida em que objetiva atingir seu público da maneira mais eficiente possível, passando a mensagem de uma forma objetiva. Se conseguirmos unir a mídia às escolas, conseguiremos agilizar e democratizar a educação.

\section{Abstract}

Changes are running more and more fast, technology is in continuous up-dating and the society with its practices and culture as well has to adapt and structure itself day after day. The education comes in this reality as a conservative process and, at the same time, as a transforming agent of knowledge and culture transmission. The midia make faster and more democratic this process while look for reaching its public by the best way as possible, and by making the message more objective.

If we get to bring together the midia and the schools, we have as a result an education more dynamic and more democratic.

\section{Introdução}

Conforme prerrogativas discutidas na Conferência Mundial sobre o Ensino Superior em Paris/1998, pude observar que a comunidade científica é a origem da maior parte das soluções técnicas e metodológicas necessárias ao desenvolvimento das Novas Tecnologias da Informação e da Comunicação (NTIC), como a Internet. No entanto, o setor da educação é paradoxalmente o campo menos beneficiado com essas novas tecnologias. Ora, o contexto atual em matéria de informação é caracterizado pela chegada maciça das soluções digitais que sacudiram as realidades instaladas. A universidade deve hoje refletir sobre os seus usos e sua penetração inelutável no mundo do ensino e da pesquisa.

Alguns pensam que o conceito de industrialização do ensino está em processo de mudança profunda. Os edifícios, as salas de aulas e os anfiteatros estarão fadados a desaparecer em favor de espaços digitais, de lugares de saber virtual? Os professores serão substituídos por avatares digitais ou serão arrastados no turbilhão da mudança? Terão eles a capacidade de definir seu papel ou sofrerão as mudanças impostas pela globalização?

As NTIC estão trazendo uma resolução na educação aberta e à distância, que lhe deveria permitir sair dos debates dos iniciados e do ceticismo dos pedagogos para transformá-la em indústria global. Os conceitos de "colaboração" e de "ensino assincrônico" deveriam começar a se impor, mais porque são o reflexo das necessidades da evolução da sociedade do que por razões puramente pedagógicas. Essa mudança traz em si os germes de uma verdadeira revolução pedagógica, onde as estruturas tradicionalmente imóveis de espaço-tempo-hierarquia vão explodir.

O conceito de universidade virtual ajuda a responder aos desafios com que se confrontarão os universitários. Ele supõe a utilização das NTIC e

\footnotetext{
*Doutorando em Educação: Currículo, PUC-SP. Mestre em Administração: Administração e Planejamento. Especialista em Ciência da Computação, Didática do Ensino Superior, Administração de Empresas. Bacharel em Administração. Professor das Faculdades Integradas "Campos Salles".
} 
uma combinação em "justa proporção" dos diferentes instrumentos tecnológicos, na perspectiva de uma mudança radical da equação do custo do ensino. A pedagogia que acompanha o novo paradigma tecnológico permite uma visão participativa da formação, favorecendo uma aprendizagem assincrônica, uma relação entre os atores e uma formação "ao longo de toda a vida".

A universidade virtual pode ser concebida como uma "meta universidade" destinada a dar um suporte às universidades existentes, sobretudo aos esclarecimentos dos países do Sul (Cf., Oilo, 1999, p.475) ${ }^{1}$ :

- em termos de infra-estrutura de educação a distância à sua disposição:

- em termos de aconselhamento e assistência para a criação de estruturas necessária;

- em termos de conteúdos pedagógicos compartilhados;

- em termos de meios técnicos e humanos para facilitar a confecção de conteúdos pedagógicos em rede.

A chegada com toda a força das NTIC, nos próximos anos, introduzirá a questão da preparação do corpo docente para essas mudanças radicais. $\mathrm{O}$ "novo professor" deverá dominar esse novo ambiente das NTIC, estar pronto psicologicamente para uma mudança radical de papel, continuando a fortalecer e atualizar seu saber disciplinar.

A informação globaliza-se, tornando-se um "mercado". É necessário defender a liberdade de acesso à informação sob a forma de um serviço público universal destinado, em particular, ao setor pesquisa-educação.

A introdução das NTIC no ensino superior não é um perigo. $\mathrm{O}$ desequilíbrio econômico entre os países do Norte e do Sul desqualifica estes últimos. A excelência científica dos países industrializados deverá irrigar os países mais pobres através de uma lógica do co-desenvolvimento. O risco de "infopobreza” é um freio ao desenvolvimento. É, portanto, fundamental que a universidade seja o emissor preponderante da circulação do saber, a serviço de uma inteligência coletiva participativa.

\section{O papel da universidade frente às novas tecnologias}

A universidade, em face da revolução tecnológica, é igual a qualquer organização do nosso tempo. Não pode ignorá-la e deixar de aproveitar todos os seus benefícios. Evidentemente, como centro crítico e questionador por natureza, jamais será uma usuária incondicional das oportunidades criadas pela tecnologia. Mas, desconhecê-la ou deixar de aproveitá-la, quando necessário, é absolutamente imperdoável. (Cf., Marcovitch, 1998, p. 141$)^{2}$

O crescimento do volume e dos meios de acesso às comunicações exige uma nova atitude mental das pessoas e das instituições. Há mudanças em marcha irreversível que não podem passar despercebidas. Tomemos alguns exemplos, para dar ênfase a essa observação.

Já existem protótipos de automóveis multienergéticos. Gasolina, gás natural e bateria elétrica são os três energéticos que alimentam o mesmo automóvel. Isso permite a alguém vir do bairro do Morumbi, por exemplo, com gasolina, entrar no centro da cidade de São Paulo com gás natural e, se tiver que passar por algum ponto mais poluído, ligar a bateria elétrica. Com isso, o consumidor terá um automóvel com performance adequada para a estrada e outras áreas de circulação, mantendo-se igualmente mais responsável, do ponto de vista ambiental.

Na área de saúde animal, já estão sendo inseridos sensores em animais assim que nascem, para acompanhamento do seu metabolismo durante o ciclo de vida, podendo-se decidir qual a ração que deve ser consumida. Um laboratório já anunciou a modificação genética de uma vaca, para que produza leite semelhante ao leite humano.

$\mathrm{Na}$ área cardiológica, existem, em vez de marcapassos, sistemas de sensores que permitem o monitoramento de pessoas cardíacas. Se houver um fibrilamento ou interrupção do ritmo correto, é possível, imediatamente, tratá-las de formas emergenciais. Esses aparelhos vêm sendo desenvolvi-

${ }^{1}$ OILO, Didier et al. - Do tradicional ao virtual: as novas tecnologias da informação. In: Tendências da educação superior para o século XXI, Brasília: UNESCO/CRUB, 1999, p. 475.

${ }^{2}$ MARCOVITCH, Jacques. - A universidade (im)possível. São Paulo: Futura, 1998, p.141. 
dos rapidamente e logo permitirão um monitoramento contínuo.

$\mathrm{Na}$ área farmacêutica, ocorre uma grande revolução com produtos capazes de tratar doenças de origem genética, como Alzheimer. São produtos que lidam com mapas genéticos de cada indivíduo. Há novos preventivos de envelhecimento e drogas proporcionadoras de equilíbrio físico que permitem um prolongamento da esperança de vida.

Os avanços tecnológicos da química chegaram ao ponto de termos, hoje, os chamados produtos inteligentes, como o tecido cuja fibra aquece no frio e permite maior arejamento no calor. Esses produtos inteligentes aparecem também na área de transportes automotivos e aéreos. Existem tanques de gasolina para aviões que, pela própria constituição, fecham imediatamente, caso sejam perfurados. Esses tanques, desenvolvidos para o transporte aéreo militar, já foram adaptados para o transporte aéreo civil.

A telefonia celular é um exemplo de tecnologia de ruptura. Ela não é a continuidade do telefone que conhecíamos no passado. Foi desenhada para novos usos e exige novas operações. Exige não uma aprendizagem, mas uma "desaprendizagem" em relação ao passado. Espera-se do indivíduo não só que ele incorpore o novo, mas esqueça parte do velho.

Quem viveu a era da substituição da máquina de escrever elétrica, aquela de esfera, para o computador, sabe o quanto se resistiu à idéia de retirar a máquina de escrever da sala, querendo sempre mantê-la como uma espécie de refúgio visível do passado.

A informação permeia as ações da universidade. É o objetivo final da pesquisa e o que efetivamente se transmite nas atividades do ensino e de extensão. Descendente direta de estudos exploratórios desenvolvidos há décadas nos laboratórios acadêmicos, a tecnólogia da informação volta à universidade como uma espécie de criatura que desafia o criador a decifrá-la incessantemente. $\mathrm{O}$ professor Imre Simon, presidente da Comissão de Informática da USP, alerta-nos para o fato de que, a partir da década de 50, quando foi iniciada a comercialização dos computadores, a cada 18 meses vem dobrando a qualidade dos produtos disponíveis por um preço fixo. Ele revela: "Em mais 15 ou 20 anos, poderemos adquirir a capacidade computacional de um computador caseiro atual por alguns reais. Alternativamente, poderemos comprar, pelos poucos milhares de reais que eles custam hoje, um verdadeiro supercomputador cujo preço atual seria de dois milhões de dólares. Inimaginável!" O exemplo dado por Simon transmite uma idéia clara do vertiginoso ritmo de evolução desses meios e conseqüente urgência de dominá-los a cada dia, principalmente na universidade, onde o conhecimento não pode parar um segundo sequer.

A universidade, como as pessoas, deve "desaprender" certos métodos, embora mantendo intacto o seu cabedal de conhecimentos. Não se trata de renunciar ao passado, mas preparar-se para o futuro com sabedoria, lançando mão das armas disponíveis.

A palavra impressa provocou uma revolução científica até 1800 e uma revolução tecnológica que começou a partir de então. Por quê? Porque a palavra impressa tornou acessível uma quantidade de informação que estava reservada a uma minoria. Quem leu O nome da rosa, de Umberto Eco, lembra o quanto era difícil ter acesso aos manuscritos. Somente as igrejas tinham a possibilidade de guardá-los e alguns eram tão secretos a ponto de serem envenenados, para que os que manuseassem as suas páginas não sobrevivessem.

Houve, na história, duas transições fundamentais: uma da palavra falada para a palavra escrita, que permitiu as primeiras revoluções, e uma segunda, a partir de 1500, da palavra escrita para a palavra impressa. Vivemos hoje um fenômeno semelhante com a palavra digital. $\mathrm{O}$ que se pode antecipar é que a mesma evolução de mentalidade que ocorreu ao longo desses últimos cinco séculos deve ocorrer, agora, numa intensidade ainda maior. $\mathrm{O}$ grande desafio que teremos pela frente será como preparar nossos quadros de referência, para lidar com essa quantidade de informações e saber selecionar o que precisamos, dentro da extraordinária disponibilidade existente.

As NTIC são facilmente captadas pelos jovens. Quando um equipamento é levado para casa, os filhos abrem a caixa e já começam a usar. Os pais descobrem a tecnologia com a leitura de um manual. Os avós distanciam-se da nova máquina, que os assusta e incomoda. Eles se sentem inferioriza- 
dos diante de uma criança de 8 ou 14 anos que tão familiarmente opera um computador, um vídeo, qualquer sistema eletrônico. A evolução tecnológica transforma rapidamente os sistemas de produção, distribuição e consumo, mas as habilidades humanas alteram-se num ritmo bem menor.

Percebemos a existência de uma elite de inovadores na área de informática. Essas pessoas constituem uma família que lida com tecnologia mais avançada e acompanha a fronteira da tecnologia. Não devemos imitá-las, mas precisamos ouvi-las para melhorar nossas habilidades e incorporar com sabedoria a inovação, sem perder de vista os propósitos mais relevantes. Lembremo-nos sempre de que a tecnologia é um meio a serviço da humanidade e não o oposto.

\section{Preparando um novo ambiente de ensino/aprendizado}

Nas experiências educacionais de formação superior - sejam elas passadas ou presentes - freqüentamos vários tipos de sala de aula. A grande maioria seguia e continua seguindo o padrão usual de um monte de cadeiras voltadas para o quadro-negro e uma mesa de professor bem imponente em cima de um tablado. As aulas ainda centradas no professor, o "locus" arquitetônico da sala, e nunca no aluno. Raramente abrimos a boca para emitir nossa opinião, e a maior parte dos alunos houve o resumo de algum livro, sem um décimo da emoção e dos argumentos do autor original, obviamente com inúmeras honrosas exceções. (Kanitz, 1999, p.21)

Nossos alunos, na maioria, encontram-se desmotivados, cheios das aulas. É só lhes perguntar, de vez em quando. Alguns professores adoram ser o centro das atenções, mas muitos estão infelizes com sua posição de ator obrigado a entreter por cinqüenta minutos um bando de desatentos.

Não é por coincidência que somos uma nação facilmente controlada por políticos mentirosos e intelectuais espertos. Nossos arquitetos do conhecimento valorizam a autoridade, não o indivíduo. Nossas salas de aula geram alunos intelectualmente passivos, e não líderes; puxa-sacos, e não colaboradores. Elas incentivam a ouvir e obedecer, a decorar, e jamais a ser criativo.
Uma das propostas de sala de aula deve ter o layout físico em formato de anfiteatro, onde os alunos ficam num plano acima do professor, não abaixo. Construídas em forma de ferradura ou semicírculo, de tal modo que cada aluno consiga olhar para os demais. O objetivo não é a transmissão de conhecimento por parte do professor, esta é a função dos livros, não das aulas.

As aulas devem exercitar a capacidade de raciocínio dos alunos, dotar e desenvolver suas habilidades de futuros profissionais. Aprenderem a ser objetivos, mostrar liderança, a resolver conflitos de opiniões, a chegarem a um comum acordo e obter ação construtiva. Como professores, temos que convencer nossos alunos a solucionarem problemas de ordens administrativas e sociais. Infelizmente, em nosso país, essas idéias só ficam nas teorias.

No Brasil, mais especificamente no ensino de graduação, nem sequer os alunos se olham nos rostos, muito menos nos olhos uns dos outros e, quando alguém vira a cabeça para o lado, é chamado à atenção. O importante neste país é anotar as pérolas da sabedoria.

Talvez seja por isso que tão poucos brasileiros escrevem e expõem suas idéias. Todas as nossas reclamações são dirigidas ao governo - leia-se professor - e nunca olhamos ao lado para trocar idéias e, quem sabe, resolvermos os problemas sozinhos.

Com base nisso, vale a pena repensarmos em novos ambientes de aprendizado, pois, com a grande e constante transformação na comunicação social e profissional, assiste-se, nos últimos cinqüenta anos, a proliferação de várias tecnologias de comunicação que permitem diminuir as distâncias entre professores e alunos, escola e sociedade, escolas e empresas, e fazer a informação chegar aos mais remotos lugares.

\section{O fim das distâncias na educação}

Fundamentado nas minhas últimas aulas, pude constatar que, nos próximos 25 anos, sofreremos as mais rápidas mudanças tecnológicas que o mundo jamais presenciou. Que efeito isso terá sobre nossas vidas? Em geral, as pessoas exageram os efeitos de curto prazo das mudanças tecnológicas e substimam as de longo prazo. Mudanças realmente notáveis atingem nossos lares, nossos hábitos 
diários, a maneira como pensamos e falamos. Consideremos as relações entre automóveis e crime, ou entre eletricidade e edifícios, ou entre televisão e vida social. Cada um desses avanços tecnológicos teve conseqüências que ninguém poderia ter previsto. A revolução nas comunicações terá conseqüências igualmente penetrantes, pessoais e surpreendentes.

Muitos temem esse futuro. Visualizam uma sociedade de pessoas isoladas, presas dentro de casa, permanentemente diante de uma tela, perdendo o gosto por contatos e experiências humanas. Preocupam-se com a exclusão dos pobres, dos idosos e dos que não têm habilidade para ligar um modem. Imaginam uma nova classe dos "sem-tecnologia", tão despreparada socialmente quanto uma pessoa sem automóvel ou sem carteira de motorista. Prevêem um mundo de perda de privacidade. Fora dos Estados Unidos, as pessoas temem um futuro no qual todo mundo fale inglês e pense como um americano, e em que a diversidade cultural seja solapada por valores fúteis hollywoodianos.

De fato, o maior impacto do fim das distâncias será tornar mais convenientes a comunicação e o acesso a informações em todas as suas formas. $\mathrm{O}$ resultado certamente será bom para todas as sociedades, embora a natureza do efeito vá depender do motivo que levará as pessoas a se comunicarem, o tipo de conhecimentos que elas vão escolher e de como elas usarão esses conhecimentos. Da mesma forma que o automóvel, a tecnologia das telecomunicações será uma ferramenta que tanto poderá ser usada para bons quanto para maus propósitos, mas deve tornar mais fácil a vida das pessoas. Mais comunicação é quase sempre melhor que menos.

Em termos gerais, a sociedade dos países ricos poderá ser alterada de quatro maneiras principais. O papel do lar mudará. O lar requerirá funções que foram perdidas ao longo do último século, tornando-se não apenas uma oficina de trabalho, mas um lugar onde as pessoas receberão a maior parte de sua educação, treinamento e assistência médica. Novos tipos de comunidades serão desenvolvidas, ligadas eletronicamente através da distância, par- tilhando trabalho, interesses domésticos, aprendizado e experiências culturais. Tanto o uso da língua inglesa quanto a força das culturas locais serão incrementados. O inglês será o idioma global, más muitas línguas regionais reflorescerão. E, para finalizar, os jovens, especialmente os inteligentes e com boa escolaridade, serão os vencedores no novo mundo eletrônico, e países jovens ganharão uma posição de vantagem sobre os mais velhos.

As sociedades serão diferentes, as comunidades terão novos moldes e as pessoas estarão acostumadas com coisas que hoje parecem estranhas. Mas as maiores mudanças serão as mais demoradas. $\mathrm{O}$ fim das distâncias vai moldar o mundo, a partir de meados do século XXI, muito mais profundamente do que o da próxima década.

Por outro lado, ao observar o universo educacional, constato que o custo da atual educação é um incentivo ao ensino à distância, principalmente no nível universitário, no qual possuo maior vivência. Ensino à distância não é novidade: a Britain's Open University oferece cursos por rádio e televisão há mais de 25 anos, enquanto nos Estados Unidos mais de 30 programas oferecem cursos universitários, principalmente de engenharia, para pessoas de regiões isoladas. Recentemente, o Brasil entrou nesse cenário com a Uvb e a UFRS, porém, uma das universidades mais antigas com cursos à distância é a Universidade da África do Sul, onde Nélson Mandela, da África do Sul, e Robert Mugabe, do Zimbábue, receberam seus diplomas.

Nesses países mais pobres, $90 \%$ do orçamento da educação é gasto com os professores, portanto, a maneira mais fácil de reduzir custos é aumentar o tamanho das salas de aula. Nesse caso, a China bateu o recorde: a Central China Television University tem de um a dois milhões de alunos, mais que todos os alunos do mundo, de ensino à distância, somados. Os cursos são bastante simples: uma câmera de televisão enquadra o professor, e a aula é transmitida via satélite para salas de aula espalhadas pelo país inteiro. Mas, para muitos países, um programa semelhante pode ser a única alternativa, principalmente para a educação de nível superior. (Cf., Cairncross, 2000, p. 319) ${ }^{3}$

${ }^{3}$ CAIRNCROSS, Frances. - O fim das distâncias: como a revolução nas comunicações transformará nossas vidas. (Trad. Edite Sciulli e Marcos T. Rubino) São Paulo: Nobel, 2000, p. 319. 
O ensino à distância é principalmente vantajoso em lugares onde as comunidades se encontram dispersas. A Universidade do Pacífico Sul tem uma rede via satélite ligando seu campus em Suva, Fidji, com sua faculdade de agricultura em Samoa Ocidental e, em outros centros, em nove países nas ilhas do Pacífico. O resultado tem sido economia de tempo e de custos de viagem dos funcionários e um declínio no número de desistências de alunos.

Mesmo nos países ricos, o treinamento e o ensino de nível superior à distância, cada vez mais serão ministrados em cursos especiais nas empresas ou em outros locais, como é típico nos Estados Unidos, ou para estudantes em suas casas (e, em alguns casos, em suas celas de prisões) como é tradicional na Grã-Bretanha e África do Sul, onde tendem a crescer. Técnicas desenvolvidas por empresas como Hewlett-Packard e Xerox chegarão aos campi somente quando os pais não se dispuserem mais a pagar o preço da educação superior dos filhos. Em 1995, as universidades particulares nos Estados Unidos cobravam perto de US $\$ 60$ por aula - um valor que desde então vem subindo, e que não conta com ajuda pública nem privada. Não obstante, uma pesquisa entre os alunos mostrou que apenas $31 \%$ acha que o pagamento das mensalidades da faculdade oferece um "bom", ou mesmo "médio", retorno pelo preço pago. $\mathrm{O}$ ensino à distância pode não ter as vantagens do nome de uma universidade famosa, mas será tão bom quanto uma universidade média e terá um custo menor. (Cf., Cairncross, 2000, p. 319) ${ }^{4}$

\section{O novo professor e suas características para NTIC}

O professor dos tempos atuais precisa possuir algumas características, para que possa atuar de forma produtiva e eficaz. O ponto fundamental nos tempos atuais é de que a visão egoísta seja substituída pela cooperação, deve-se encontrar com o outro e também ajudá-lo a fazer as coisas, as decisões devem refletir o trabalho do grupo e não de uma só pessoa.

Em função disso, por não existir mais a separa- ção nítida entre quem ensina e quem aprende, as pessoas não podem mais ser medíocres, desatualizadas e pouco reflexivas.

Há necessidade de todas se esforçarem para obter atualização, acompanhando o surgimento de novos conhecimentos e novas técnicas. As pessoas, paralelamente, precisam ter habilidades para trabalhar em grupo, demonstrando serem capazes de se relacionar com os outros.

Conseqüentemente, passa a se exigir que os indivíduos tenham uma sólida formação humanista, capacitando-os a vivenciar um novo tipo de relação interpessoal nas escolas, na sociedade e no trabalho profissional.

Mas, como a decisão envolve a todos, além de ter certa especialização numa determinada área, há necessidade de que as pessoas também sejam generalistas, melhorando a qualidade da decisão, pois só assim contemplarão um maior número de variáveis e, conseqüentemente, a análise da situação e das alternativas será mais rica.

Paralelamente, os valores éticos de parceria, sinceridade, dignidade, amizade, cooperação, fidelidade e confiança devem ser praticados tanto pelas pessoas como pelas organizações, como chave para o sucesso.

O homem contemporâneo, fruto de um novo momento histórico, deverá aprender a conviver cada vez mais dentro de uma nova ética. Assim, deverá existir um esforço em abandonar as práticas anteriores, fruto de um momento histórico em que a exploração, mentira, egoísmo, orgulho e desonestidade eram os valores praticados, mesmo que de forma disfarçada.

A mudança de comportamento das pessoas afetará significativamente o homem e o tornará mais ético, respeitador do próximo, defensor dos Direitos Humanos.

A capacitação profissional do educador visa o futuro, que inicia a partir do momento que começamos a pensar no amanhã. Assim: "O futuro é sempre o primeiro minuto, a próxima hora ou o dia seguinte".

Às vezes, acomodados nas circunstâncias do presente, esquecemos o futuro, mais ainda das transformações que nos conduzem a ele. Por isso,

${ }^{4}$ Ibid, p. 319. 
cabe ou é oportuno, de vez em quando, fazer-nos um "alerta para o futuro", propiciando nossa participação, consciente, nos acontecimentos importantes e marcantes da época, e não sermos surpreendidos por algo que acompanhou nosso dia-a-dia, sem que conseguíssemos participar dele.

Logo, cabe observarmos que tanto os professores quanto as instituições de ensino superior deverão, nestas próximas décadas, buscar incorporar as mudanças necessárias, para que possam assumir as novas posturas exigidas pela sociedade e pelo mercado de trabalho.

A educação continuada, exigida de todos, tanto das organizações quanto das pessoas ${ }^{5}$, será o fator preponderante e demandará de ambos um esforço muito grande para acompanharem as inovações e novas descobertas.

As NTIC, valorizando os bits, tornarão possíveis ações até então inviáveis ou desconhecidas e darão origem a novas concepções de tempo e espaço. O real, o virtual e o pessoal darão origem a novas concepções de coisas e de pessoas, fazendo surgir novas formas de relacionamento e alterando significativamente o mercado de trabalho.

A palavra chave será informação. Quem a possuir e souber utilizá-la corretamente, com certeza se destacará dos demais, pois terá nela o alimento fundamental do processo de tomada de decisão, o que representa a sobrevivência para qualquer empresa e/ou indivíduo. Além da informação, as pessoas terão de ser rápidas na tomada de decisão, pois de nada adiantará ter informações em tempo real e a tomada de decisão acontecer a "passo de tartaruga". Assim, a rapidez na tomada de decisão será o grande diferencial que separará os vencidos dos vencedores. Entretanto, além dessa preocupação, os homens e as organizações deverão incorporar nas suas ações de valores que contemplem o respeito à vida e à natureza. $\bigcirc$ direito à vida passa a ressaltar a importânncia da natureza e os animais, com preservação das espécies. Quem não respeitar a natureza e os animais, com certeza não terá espaço nessas próximas décadas. A nova geração terá esses valores sedimentados e bastante presentes na forma de ser, agirá naturalmente na preservação e conservação não só do homem, mas também do planeta e da própria essência da vida.

Portanto, na atual conjuntura, as pessoas e as organizações terão que estar preparadas para começarem a viver nesse novo mundo, mesmo porque ele se delineia como algo que será bastante contrário ao que significou a vida na terra, especialmente no período posterior à revolução industrial.

Assim, apesar de toda adversidade, o ser humano e as organizações estão tendo o privilégio de viver um dos momentos históricos mais importantes da humanidade, pleno de desafios e também de grandes oportunidades. Não o reconhecer e não o aproveitar como tal será uma perda lastimável, pois momentos históricos tão marcantes quanto estes acontecem somente após centenas ou milhares de anos.

É por tudo isso que não poderemos perder essa oportunidade de crescimento e desenvolvimento, absorvendo novos conhecimentos, técnicas e, o mais importante, desenvolvendo respeito ao semelhante, a si mesmo e à natureza, essencial à vida humana, apesar de ter sido prejudicada durante séculos.

Entretanto, vale lembrar que o professor deve ser visto como o principal elemento (agente) de mudança educacional da sociedade, por este motivo deverá estar cada vez mais preparado e qualificado para essa nova realidade.

\section{Aprender a aprender com as NTIC: um tema polêmico}

No desenvolvimento da ciência cognitiva e suas derivações em educação, produziu-se um movimento a favor do ensino de estratégias gerais de pensamento que tiveram pouco impacto. Ensinaram-se técnicas de estudo sublineado, anotações, identificações de idéias principais e secundárias em um texto etc. Eram programas separados do corpo das cadeiras. Baseavam-se no pressuposto de que era muito difícil para os alunos aprenderem simultaneamente o conteúdo de uma disciplina e aprenderem a aprender. No entanto, estas habilidades aprendidas não eram transferidas espontaneamente para as disciplinas nem para fora dos programas

${ }^{5}$ Consulte obras mais específicas, tais como: Educação corporativa de Jeanne C. Meister, Ed. Makron Books; Re-educating the corporation: foundations for the learning organization, Daniel R. Tobin, Paperback. 
nos quais tinham sido ensinados. Um aluno de qualquer nível pode se tornar um "perito" em identificar, por exemplo, idéias principais num texto, e elaborar resumos sem compreender cabalmente o significado das expressões ou dos termos que formam o texto. As estratégias gerais necessitam de um conhecimento de base sobre o qual operar. A proposta aqui seria reconhecer a necessidade de um conhecimento específico num domínio particular, no qual as estratégias selecionadas sejam também específicas, apropriadas para as tarefas que se tenta desenvolver e integradas com a aprendizagem de uma disciplina escolar.

Neste sentido, as NTIC - como o acesso a redes de informação e o uso do correio eletrônico - redefiniriam as tarefas intelectuais. Não se trata de encher disquetes com informações, do mesmo modo como em certas propostas didáticas se enchem pastas com recortes de jornais que ninguém lê, nem de acumular folhetos que ninguém consulta, mas de utilizar um meio para ter acesso a nova informação realmente necessária e com possibilidades de ser transformada no contexto de uma atividade e de um conteúdo específico.

É necessário, desde a escola de ensino superior, ingressar nas culturas dos filósofos, dos sociólogos, dos psicólogos, dos escritores, dos críticos literários etc. A instituição de ensino superior deverá evoluir de tal modo que possa formar consumidores informados, intérpretes ou especialistas no campo dos domínios críticos de ciência, engenharia, economia, educação etc. No campo das artes, por exemplo, muitas vezes se optou por formar somente intérpretes ou nada. Poucos serão alunos que no futuro sejam músicos, artistas plásticos ou escritores; alguns poderão ser críticos de arte, mas muitos deles podem chegar a ser consumidores informados.

Para poder ingressar nos sistemas de crenças dos especialistas num domínio é necessário aproximar a escola destas culturas para estabelecer um diálogo com elas.

A escola superior deve poder delinear ações pertinentes neste sentido, de modo a possibilitar lenta e gradualmente a passagem de novato a perito, e contribuir na formação de quem, em psicologia cognitiva, se denomina "novatos inteligentes": alunos que, embora não possuam o conhecimento necessário num novo campo, sabem como iniciar um caminho para ter acesso a esse conhecimento.

Em síntese, se reconhecermos que nós mesmos, docentes, enriquecemos nosso trabalho ao compartilhá-lo com os demais; que, para levá-lo a cabo, necessitamos de nossos apontamentos e nossos livros; que, para apresentar certos tipos de informações, fazemos uso de organizadores gráficos; que continuamos "aprendendo a aprender", à medida que elaboramos informes de atividades, apresentamos nossas experiências de aula a outros docentes ou elaboramos projetos de trabalho, e que os anos de trabalho, a avaliação de nossas práticas docentes e a reflexão sobre elas nos fazem cada vez mais peritos em questões de ensino, então estes princípios podem e devem se refletir em nossas práticas de ensino.

Um aluno parado na frente durante uma aula recitando um texto, memorizado para a ocasião, para companheiros que não prestam atenção e para um docente que já conhece o conteúdo daquilo que se recita, constitui uma contradição profunda entre o que, como docente, se vive, pensa ou sente e a exigência de memorização que, ainda hoje, sobrevive em algumas aulas universitárias brasileiras.

A Internet e/ou o e-mail podem ser ferramentas a mais, para que se realizem consultas pertinentes a peritos, trabalhe-se com um grupo de alunos de diversos lugares de nosso país ou de outro, e para que se dominem, gradualmente, as possibilidades que abrem as NTIC.

Sem dúvida, a Internet e o correio eletrônico podem abrir novas formas de interação entre alunos e docentes de diferentes instituições escolares de nível superior, localizadas em contextos geográficos e culturais diferentes. Pode abrir um caminho para aprender a se comunicar com outros que ensinam e aprendem (docentes universitários, pesquisadores, figuras do meio político e cultural, peritos num domínio etc.).

O intercâmbio entre acadêmicos não é novo. Nas bases pedagógicas da escola moderna de Freinet, já se tratava a comunicação entre instituições situadas em diferentes espaços geográficos utilizando o correio postal.

Talvez o que faça falta seja certa dose de audácia para participar de situações de intercâmbio que 
possam apresentar mais riscos que as classes convencionais, onde o controle é dado pelo ritmo das explicações, o desenvolvimento das atividades dentro da aula, as perguntas e respostas que possam emergir etc.

Em nosso país, já estão se desenvolvendo alguns projetos experimentais neste sentido (PUC/ SP, Faculdades Oswaldo Cruz, Universidade Anhembi-Morumbi, Fundação Getúlio Vargas etc.) e, provavelmente, estes começarão a ser avaliados, melhorados e exibidos para a comunidade educacional daqui a pouco tempo.

Sem a menor sombra de dúvida, os computadores haverão de produzir mudanças profundas nas modalidades de ensino e aprendizagem. Não se trata de modernizar o cenário da universidade com aparelhos sofisticados, mas de começar a visualizar pontes para comunicarem-se as instituições de ensino superior entre si. As NTIC parecem ser um dos caminhos possíveis. Não é o único, mas é viável.

\section{A WWW na prática da educação à distância}

"Educação à Distância (EaD) é uma metodologia desenhada para aprendentes adultos, baseada no postulado que, estando dada sua motivação para adquirir conhecimento e qualificações e a disponibilidade de materiais apropriados para aprender, eles estão aptos a terem êxito em um modo de auto-aprendizagem" (Trindade, 1992 , p. 52$)^{6}$.

A partir dos anos 90, a Internet abre uma possibilidade de se ampliar o ambiente acadêmico para além da sala de aula, conforme descrito anteriormente. Setores especialistas em Ead, nas mais diferentes instituições educacionais, não só abrem espaços para uma comunicação mais interativa entre professores e alunos de $\mathrm{EaD}$, como possibilitam que essa interação sề estenda até especialistas, produtores de material didático tanto aqueles, particularmente, preocupados com a $\mathrm{EaD}$, quanto os que se dedicam à educação em geral. A popularização que a WWW (World Wide Web), na Internet, tem alcançado - a partir de 1996 - amplia as possibilidades de sua utilização como tecnologia da EaD. Professores como Garcia ${ }^{7}$ vêm realizando diversas pesquisas, oficinas de formação de professores orientando-os não só na construção como também na confecção de páginas da WWW para a distribuição de informação, consultoria e tutoria à distância. É um novo ambiente educacional, virtual, que os alunos (dos cursos presenciais ou à Distância) têm à sua disposição e que bem desenhado permite uma combinação bastante rica.

Os trabalhos sobre EaD têm se multiplicado à medida que cresce a necessidade de uma educação contínua, por toda a vida, enquanto que as facilidades para se freqüentar cursos presenciais diminuem. As tecnologias de EaD são procuradas para que se possa promover a capacitação e a atualização nas mais diversas áreas do conhecimento.

Observa-se que há uma reavaliação da utilização das mídias impressas, buscando-se adequá-las a um discurso mais direto, interativo, motivador, apropriado para uma comunicação à distância, complementado o textual verbal com o visual através de desenhos, figuras, mapas, quadros, complementando. Proliferam os materiais impressos acompanhados de fita de áudio e fitas de vídeo. Os estudos das últimas décadas, enfatizando a existência de múltiplas inteligências, os diferentes estilos de aprendizagem, servem como suporte à utilização dessas tecnologias na EaD.

E aqui se considera EaD tanto aquela totalmente feita sem o contato presencial de professores e alunos quanto a complementar da educação feita nas escolas de Ensino Fundamental, Ensino Médio ou de Ensino Superior. Quando se seleciona um documentário da National Geographic e solicita-se aos alunos a sua análise, bem como os comentários críticos, após um trabalho feito em casa com o suporte dessas mídias, ou quando se indica um programa televisivo educacional com uma produção escolar a ser desenvolvida pelos alunos, ou, ainda, quando se faz um acompanhamento através do correio eletrônico, o que o professor está fazendo é, exatamente, usar tecnologias de $\mathrm{EaD}$, como outros mediadores de sua orientação aos alunos, distante do ambiente escolar tradicional. Isto é, o

${ }^{6}$ TRINDADE, A. R. - Distance education for europe. Lisboa: Universidade Aberta, 1992, p. 52.

7Dra. Marilena Santos Santana Garcia, professora de Pós-Graduação da Universidade Anhembi-Morumbi. 
ambiente social onde se insere a TV, o vídeo, as redes de computadores, transforma-se momentaneamente em um ambiente educacional.

Observa-se, porém, que aqueles educadores que ainda praticam um paradigma educacional tradicional, dentro do conceito de comunicação hipodérmica - em que o conhecimento é transmitido de um emissor ativo (o professor) para um receptor passivo (o aluno) - consideram EaD o ensino por correspondência para adultos que não puderam freqüentar a escola na idade apropriada. EaD é muito mais amplo e define que não é feita no ambiente escolar tradicional, podendo ser desenvolvida como parte complementar da educação escolar formal praticada em instituições educacionais. Nesse sentido, as tecnologias de comunicação social se transformam em tecnologias de EaD.

Na Universidade de São Paulo, alguns professores desenvolveram e continuam desenvolvendo projetos de formação contínua de professores, utilizando-se dessas tecnologias. Textos complementados por uma bibliografia específica, por fitas de vídeo e/ou fitas de áudio são trabalhados em sua casa ou nos ambientes de trabalho, nas horas livres, por professores que necessitam atualizar-se e têm horas limitadas para esse desenvolvimento. De forma que, ao encontrarem-se presencialmente, o debate poderá ser mais objetivo e produtivo. Com a proliferação de provedores de serviço, a Internet vem sendo cada vez mais utilizada nessa intercomunicação à distância entre professores e alunos, entre especialistas e professores, entre alunos e alunos.

Devemos relembrar que o ambiente já não está mais restrito às quatro paredes da sala de aula, mas estende-se a qualquer lugar em que indivíduos de todas as idades, do Ensino Fundamental ao Ensino Superior, se encontrem realizando atividades escolares de aprendizagem mediados pelas tecnologias da comunicação, aqui ditas tecnologias de $\mathrm{EaD}$.

Vale ressaltar e reforçar que a $\mathrm{EaD}$ viveu uma longa história de pesquisas e de realizações, partindo dos estudos por correspondência até os sistemas apoiados em audiovisuais à distância (em geral com base em satélite). As NTIC estão trazendo uma revolução nessa disciplina e deveriam permitir-lhe sair dos debates entre iniciados e do ceticismo dos pedagogos para transformá-la em indústria global.
Enquanto a questão da qualidade pedagógica da EaD continua objeto de inúmeros debates contraditórios entre "tradicionalistas" e "especialistas", as NTIC começam a introduzir todos os elementos de uma verdadeira revolução pedagógica, onde as relações professores/alunos e alunos/alunos vão mudar radicalmente. Os conceitos de "colaboração" e de "ensino assincrônico" deveriam começar a se impor, mais porque são reflexos das necessidades da evolução da sociedade que por razões puramente pedagógicas. Entretanto, essa mudança traz os germes de uma verdadeira revolução pedagógica, na qual as estruturas tradicionalmente imóveis de espaço-tempo-hierarquia vão explodir. $\mathrm{O}$ argumento principal que clama por essa mudança é, evidentemente, econômico; é preciso estar consciente, por outro lado, de que as tarifas do EaD continuam ainda hoje no patamar das do ensino tradicional, não tendo sido ainda alcançada a economia de massa que permite rentabilizar um investimento inicial superior, sob todos os pontos de vista, ao do ensino tradicional. Isto mudará radicalmente na fase de massificação dessa tecnologia, que poderá acontecer após um período de transição de alguns anos.

Restam, naturalmente, inúmeros desafios a enfrentar:

- a utilização de diferentes tecnologias nas proporções e usos apropriados;

· a questão da avaliação de professores e alunos;

· a questão da propriedade intelectual dos conteúdos;

- mais importante ponto de estrangulamento: a formação (em particular a dos professores) para o domínio do uso desses instrumentos novos.

\section{Considerações finais}

A universidade está hoje em condições de enfrentar o desafio das novas tecnologias da informação e da comunicação. Para fazê-lo, ela deve desencadear um processo de trabalho cooperativo no qual os países menos avançados terão um lugar importante. A excelência científica dos países industrializados deverá irrigar os países mais pobres, a partir da lógica do co-desenvolvimento. $\mathrm{O}$ risco de uma infopobreza constitui um freio ao desenvolvimento. É portanto fundamental que a Uni- 
versidade seja o emissor preponderante da circulação do saber a serviço de uma inteligência coletiva. Na perspectiva do "saber transnacional", ela deverá levar em consideração a validação do que for adquirido e a diplomação, cujas modalidades deverão evoluir.

Em sua reconfiguração, a universidade deverá, a partir de agora, funcionar segundo duas formas, colocadas em complementaridade, a dimensão tradicional e a contribuição das novas tecnologias. Pois, temos consciência que a educação no Brasil está obsoleta, mas sabemos também que aos poucos está se transformando e se adequando às novas realidades. Devemos acreditar e lutar por melhoras neste setor, pois ele é a base para a construção de uma sociedade melhor.

\section{REFERÊNCIAS BIBLIOGRÁFICAS}

AGGARWAL, Anil - Web-based learning and teaching technologies: opportunities and challenges. London : Idea Group Publishing, 2000.

BELLONI, Maria L. Educação à distância. Campinas: Autores Associados, 1999.

CARVALHO, Paulo S. Interação entre humanos e computadores: uma introdução. São Paulo: EDUC, 2000.

FAZENDA, Ivani C. A. et al. Interdisciplinaridade e novas tecnologias: formando professores. Campo Grande: UFMS, 1999.

FRANCO, Marcelo A. Ensaio sobre as tecnologias digitais da inteligência. Campinas: Papirus, 1997.

GRINSPUN, Míriam P. S. Z. et al. Educação tecnológica: desafios e perspectivas. São Paulo: Cortez, 1999.

LAGUERRE, Christian. École, informatique et nouveaux comportements. Paris: L'Harmattan, 1999.

LITWIN, Edith. et al. Tecnologia educacional: política, historias e propostas. (Trad. Ermani Rosa). Porto Alegre: Artes Médicas, 1997.

MAIA, Carmen. Ead. br: Educação à distância no Brasil na era da internet. São Paulo: Anhembi-Morumbi, 2000.

MORAES, Raquel A. Informática na educação. Rio de Janeir : DP\&A, 2000.

MORAN, José M. et al. Novas tecnologias e mediação pedagógica. Campinas: Papirus, 2000.

OLIVEIRA, Jayr F. Uma reflexão dos impactos da tecnologia da informação no Brasil: a visão da sociedade, das empresas e dos sindicatos. São Paulo: Érica, 1999.

POUTS-LAJUS, Serge; RICHÉ-MAGNIER. L'école à l'heure d'internet: les enjeux du multimédia dans l'éducation. Paris: Nathan Pédagogie, 1998.

TENÓRIO, Robinson M. Cérebros e computadores: a complementaridade analógica-digital na informática e na educação. São Paulo: Escrituras, 1998.

VALENTE, José A. et al. O computador na sociedade do conhecimento. Campinas: UNICAMP/NIED, 1999. 